\title{
Clearance of inhaled technetium-99m-DTPA as a clinical index of pulmonary vascular disease in systemic sclerosis
}

\author{
O.M. Kon*, Z. Daniil*, C.M. Black+, R.M. du Bois*
}

Clearance of inhaled technetium-99m-DTPA as a clinical index of pulmonary vascular disease in systemic sclerosis. O.M. Kon, Z. Daniil, C.M. Black, R.M. du Bois. (CERS Journals Ltd 1999.

ABSTRACT: This study evaluated the utility of the clearance time of inhaled diethylenetriamine pentaacetate (DTPA) to distinguish pulmonary vascular disease from early fibrosing alveolitis (FA) in patients with systemic sclerosis (SSc). It was hypothesized that this would be preserved in patients with vascular disease compared with FA, despite similar gas-transfer deficits and matching lung volumes, because of the preservation of alveolar epithelial integrity.

All patients had SSc and were categorized into a control group $(C ; n=9)$, pulmonary vascular group (VAS; $n=14)$ or FA group $(n=14)$ dependent on the appearance on a computed tomography (CT) scan and the transfer factor of the lung for carbon monoxide ( $T$ L,CO) (VAS and FA $\leq \mathbf{7 0 \%}, \mathrm{C} \geq \mathbf{8 0 \%} \%$ ). All patients had a forced vital capacity (FVC) of $>80 \%$.

The TL,CO (median) was similar in the VAS $(57.5 \%)$ and FA $(60 \%)$ groups. There was a significant difference in median DTPA clearance half-times between FA $(21.25$ $\min )$ and VAS (46.5 $\mathrm{min})(\mathrm{p}=\mathbf{0 . 0 1 4})$ and between FA and $\mathrm{C}(84.5 \mathrm{~min})(\mathrm{p}=\mathbf{0 . 0 0 0 4})$. No difference was found between VAS and $C(p=0.0778)$. Follow-up data from the VAS group showed no subsequent development of FA on the CT scan and no decrease in FVC (n=13, mean 42 months).

These results suggest that clearance of diethylenetriamine pentaacetate is preserved in patients likely to have pulmonary vascular disease and may be useful in distinguishing fibrosing alveolitis from vascular disease in systemic sclerosis.

Eur Respir J 1999; 13: 133-136.

Pulmonary involvement in systemic sclerosis $(\mathrm{SSc})$ is present in $70 \%$ of patients at post mortem examination [1]. The most common pulmonary complication is fibrosing alveolitis (FA) [2], but isolated pulmonary vascular disease is also well recognized in SSc [3-6] and has also been speculated to be the cause of isolated decreases in the total diffusing capacity of the lung for carbon monoxide $(T \mathrm{~L}, \mathrm{CO})$ [7]. Isolated vascular disease has been noted in particular to be common in patients with limited disease calcinosis, Raynaud's phenomenon, oesophageal involvement sclerodactyly and telangiectasia (CREST) syndrome [8, 9]. Current therapy for predominant vascular disease in this group of patients comprises vasodilator treatment, in contrast to the immunosuppressant regimens used for FA in SSc. Differentiating these two pulmonary complications of $\mathrm{SSc}$ is, therefore, of practical significance.

An isolated decrease in TL,CO with preserved lung volumes and a normal chest radiograph is suggestive of the presence of pure pulmonary vasculopathy and has been described previously [10]. High-resolution computed tomography (HRCT) can increase the sensitivity of identification of FA, but absolute confirmation to differentiate vasculopathy from early FA has required invasive biopsy procedures.

Inhaled technetium-labelled diethylenetriamine pentaacetate ${ }^{99 \mathrm{~m}}$ Tc-DTPA) clearance times have previously been shown to be abnormal in SSc patients with FA [11, 12] and to be useful in predicting the clinical course of their parenchymal disease [13]. There is also evidence that
*Interstitial Lung Disease Unit, Royal Brompton Hospital, London, UK. ${ }^{+}$Dept of Rheumatology, Royal Free Hospital, London, UK.

Correspondence: R.M. du Bois Interstitial Lung Disease Unit Royal Brompton Hospital

Sydney Street

London SW3 6NP

UK

Fax: 441713518336

Keywords: Fibrosing alveolitis pulmonary vascular disease systemic sclerosis technetium-99m-diethylenetriamine pentaacetate

Received: August 311998

Accepted after revision February 261998
${ }^{99 \mathrm{~m}}$ Tc-DTPA clearance times may also be abnormal before plain chest radiograph [14] and computed tomography (CT) [11] changes in FA. Therefore, it was predicted that DTPA clearance times would be slower in predominant vascular disease in SSc than in patients with FA and SSc. This is because preservation of alveolar epithelial integrity, together with obliteration of the vascular bed (the normal route of clearance of isotope from the lung), would prevent removal of the isotope from the airspace. Therefore, ${ }^{99 \mathrm{~m}} \mathrm{Tc}$ DTPA clearance times were evaluated retrospectively in two groups of nonsmoking patients with SSc and matching abnormalities of isolated decreases in TL,CO but with normal vital capacity: 1) patients with evidence of FA on HRCT, and 2) patients with normal HRCT. For comparison, a group of SSc patients with normal imaging and physiology was also evaluated.

\section{Subjects and methods}

\section{Patients}

All patients fulfilled the American Rheumatism Association (ARA) preliminary criteria for SSc [15]. Patient groups were then characterized dependent on their presenting lung function and HRCT appearances. An abnormal total gas transfer $(T \mathrm{~L}, \mathrm{CO})$ was defined as $\geq 70 \%$ and normal lung volumes as a forced vital capacity (FVC) of $80 \%$. In the presumed pure vascular disease group (VAS), 14 patients were identified who had isolated TL,CO of $\geq 70 \%$ of predicted, $\mathrm{FVC} \geq 80 \%$, normal chest radiographs 
Table 1. - Clinical, demographic and immunological characteristics of 37 patients with systemic sclerosis

\begin{tabular}{|c|c|c|c|c|c|c|c|c|c|}
\hline \multirow[b]{2}{*}{ Patient No. } & \multirow[b]{2}{*}{ Age yrs } & \multirow[b]{2}{*}{ Sex } & \multirow[b]{2}{*}{ Subject } & \multirow[b]{2}{*}{ HRCT } & \multirow[b]{2}{*}{ FVC \% pred } & \multirow[b]{2}{*}{$T \mathrm{~L}, \mathrm{CO} \%$ pred } & \multirow[b]{2}{*}{$\mathrm{ECHO}$} & \multicolumn{2}{|c|}{ ANA } \\
\hline & & & & & & & & Scl-70 & $\mathrm{AC}$ \\
\hline \multicolumn{10}{|c|}{ Group 1 (VAS) } \\
\hline 1 & 56 & $\mathrm{~F}$ & LSSC & $\mathrm{N}$ & 96 & 70 & $\mathrm{~N}$ & - & + \\
\hline 2 & 40 & $\mathrm{~F}$ & LSSC & $\mathrm{N}$ & 115 & 66 & $\mathrm{~N}$ & & \\
\hline 3 & 75 & $\mathrm{~F}$ & LSSC & $\mathrm{N}$ & 122 & 57 & & - & + \\
\hline 4 & 43 & M & LSSC & $\mathrm{N}$ & 104 & 42 & $\mathrm{~N}$ & - & + \\
\hline 5 & 63 & $\mathrm{~F}$ & LSSC & $\mathrm{N}$ & 117 & 33 & PHT & - & + \\
\hline 6 & 41 & $\mathrm{~F}$ & LSSC & $\mathrm{N}$ & 95 & 54 & $\mathrm{~N}$ & - & - \\
\hline 7 & 62 & $\mathrm{~F}$ & LSSC & $\mathrm{N}$ & 109 & 44 & PHT & - & + \\
\hline 8 & 50 & $\mathrm{~F}$ & LSSC & $\mathrm{N}$ & 106 & 65 & $\mathrm{~N}$ & - & + \\
\hline 9 & 38 & $\mathrm{~F}$ & DSSC & $\mathrm{N}$ & 107 & 69 & $\mathrm{~N}$ & - & - \\
\hline 10 & 47 & $\mathrm{M}$ & LSSC & $\mathrm{N}$ & 98 & 58 & $\mathrm{~N}$ & - & + \\
\hline 11 & 60 & $\mathrm{~F}$ & LSSC & $\mathrm{N}$ & 108 & 44 & $\mathrm{~N}$ & - & + \\
\hline 12 & 52 & $\mathrm{~F}$ & LSSC & $\mathrm{N}$ & 122 & 44 & $\mathrm{~N}$ & - & + \\
\hline 13 & 50 & $\mathrm{~F}$ & LSSC & $\mathrm{N}$ & 134 & 60 & $\mathrm{~N}$ & - & + \\
\hline 14 & 51 & $\mathrm{~F}$ & DSSC & $\mathrm{N}$ & 113 & 69 & $\mathrm{~N}$ & - & - \\
\hline \multicolumn{10}{|l|}{ Group 2 (C) } \\
\hline 1 & 44 & $\mathrm{~F}$ & LSSC & $\mathrm{N}$ & 103 & 84 & & - & - \\
\hline 2 & 48 & $\mathrm{~F}$ & DSSC & $\mathrm{N}$ & 113 & 110 & $\mathrm{~N}$ & - & - \\
\hline 3 & 52 & $\mathrm{~F}$ & LSSC & $\mathrm{N}$ & 98 & 86 & $\mathrm{~N}$ & - & - \\
\hline 4 & 49 & M & LSSC & $\mathrm{N}$ & 97 & 105 & $\mathrm{~N}$ & - & - \\
\hline 5 & 66 & $\mathrm{~F}$ & LSSC & $\mathrm{N}$ & 137 & 85 & $\mathrm{~N}$ & - & - \\
\hline 6 & 50 & $\mathrm{~F}$ & DSSC & $\mathrm{N}$ & 92 & 90 & & - & - \\
\hline 7 & 79 & $\mathrm{~F}$ & LSSC & $\mathrm{N}$ & 85 & 93 & $\mathrm{~N}$ & + & - \\
\hline 8 & 41 & $\mathrm{~F}$ & DSSC & $\mathrm{N}$ & 89 & 80 & $\mathrm{~N}$ & - & - \\
\hline 9 & 54 & $\mathrm{~F}$ & DSSC & $\mathrm{N}$ & 148 & 88 & $\mathrm{~N}$ & - & - \\
\hline \multicolumn{10}{|c|}{ Group 3 (FA) } \\
\hline 1 & 42 & $\mathrm{M}$ & DSSC & FA & 85 & 63 & $\mathrm{~N}$ & + & - \\
\hline 2 & 61 & $\mathrm{~F}$ & LSSC & FA & 88 & 54 & $\mathrm{~N}$ & - & - \\
\hline 3 & 24 & $\mathrm{~F}$ & DSSC & FA & 104 & 60 & $\mathrm{~N}$ & - & - \\
\hline 4 & 46 & $\mathrm{~F}$ & DSSC & FA & 122 & 60 & $\mathrm{~N}$ & - & - \\
\hline 5 & 29 & $\mathrm{~F}$ & LSSC & FA & 88 & 52 & & - & - \\
\hline 6 & 49 & $\mathrm{~F}$ & LSSC & FA & 88 & 56 & & & \\
\hline 7 & 48 & $\mathrm{~F}$ & LSSC & FA & 94 & 69 & $\mathrm{~N}$ & - & - \\
\hline 8 & 47 & $\mathrm{~F}$ & DSSC & FA & 90 & 54 & $\mathrm{~N}$ & - & - \\
\hline 9 & 51 & $\mathrm{~F}$ & LSSC & FA & 114 & 64 & $\mathrm{~N}$ & + & - \\
\hline 10 & 53 & $\mathrm{~F}$ & LSSC & FA & 104 & 63 & $\mathrm{~N}$ & + & - \\
\hline 11 & 43 & $\mathrm{~F}$ & LSSC & FA & 94 & 61 & $\mathrm{~N}$ & + & - \\
\hline 12 & 62 & $\mathrm{~F}$ & LSSC & FA & 102 & 46 & $\mathrm{~N}$ & & \\
\hline 13 & 30 & $\mathrm{~F}$ & LSSC & FA & 93 & 69 & $\mathrm{~N}$ & - & - \\
\hline 14 & 38 & $\mathrm{~F}$ & LSSC & FA & 92 & 52 & $\mathrm{~N}$ & + & - \\
\hline
\end{tabular}

HRCT: high-resolution computed tomography; FVC: forced vital capacity; TL,CO: transfer factor of the lung for carbon monoxide; ECHO: echocardiography; ANA: antinuclear antibodies; AC: anticentromere; VAS: pulmonary vascular; C: control; FA: fibrosing alveolitis; F: female; M: male; LSSC: limited systemic sclerosis; DSSC: diffuse systemic sclerosis; N: normal; PHT: pulmonary hypertension.

and no evidence of parenchymal disease on HRCT appearances. As a matching control group, patients with biopsy-proven FA and SSc were also characterized $(\mathrm{n}=14)$. In addition to characteristic biopsies, these patients had HRCT appearances typical of FA and, as in the VAS group, had a $T \mathrm{~L}, \mathrm{CO}$ of $\leq 70 \%$ and $\mathrm{FVC} \geq 80 \%$. An additional control (C) group comprised nine patients with SSc, but no radiographic or lung function abnormalities.

Full characteristics of all patient groups are given in table 1. All patients were nonsmokers or had stopped smoking at least 6 months before the study.

\section{${ }^{99 m}$ Tc-DTPA clearance}

Clearance of aerosolized ${ }^{99 \mathrm{~m}} \mathrm{Tc}-\mathrm{DTPA}$ from the lungs to the blood was measured as described previously [16]. An aerosol of ${ }^{99 m}$ Tc-DTPA was produced using an Acorn nebulizer (Medic-Aid, Bognor Regis, UK) and administered for $4 \mathrm{~min}$; the particle size was limited to $<2 \mu \mathrm{m}$. One- minute frames were acquired by a gamma camera (SMV International, Buc, France) for 45 min, background subtraction was employed, using activity in the central abdomen (not including the kidneys). An exponential fit was derived from the first $15 \mathrm{~min}$ of the curve (starting from peak activity) and the half-time of clearance was obtained; slow and fast components were not delineated by curvestripping. The normal range for ${ }^{99 \mathrm{~m}}$ Tc-DTPA clear-ance was defined in 22 nonsmoking volunteers (values lying within 2 SD of the mean) [11]; on this basis, a clearance half-time of $<40$ min was regarded as abnormal.

\section{Respiratory function tests}

In all patients respiratory function tests (expressed as percentages of predicted values based on age, sex, height and ethnic origin) [17] had been performed within 4 weeks of initial ${ }^{99 \mathrm{~m}}$ Tc-DTPA clearance measurement. 


\section{Autoantibody analysis}

Autoantibody analysis was performed in the Department of Immunology at the Royal Free Hospital and has been described previously [18].

\section{Statistical analysis}

All patients with SSc in the Royal Brompton Hospital database between the years 1986 and 1997 were screened and patients were selected on fulfilling the lung function and radiographic criteria outlined above. The data were collected prospectively and analysed retrospectively. TL,CO, FVC and ${ }^{99 \mathrm{~m}} \mathrm{Tc}$-DTPA clearance half-times were analysed between groups using the Mann-Whitney test.

\section{Results}

The C group ( $\mathrm{n}=9$, aged $41-79 \mathrm{yrs}$ ) had median \% pred values (range) for FVC of 98 (85-148)\% and for TL,CO of $86(80-110) \%$. The FA group $(\mathrm{n}=14$, aged $24-62 \mathrm{yrs})$ had median \% pred values for FVC of $93.5(85-122) \%$ and for TL,CO of 60 (46-69)\%. The (VAS) group $(n=14$, aged 38$75 \mathrm{yrs}$ ) had median \% pred values for FVC of 108.5 (95$134) \%$ and for $T \mathrm{~L}, \mathrm{CO}$ of $57.5(33-70) \%$. The FVC was similar in all three groups, with no significant differences between groups. However, there was a significant difference in $T \mathrm{~L}$, CO between the $\mathrm{C}$ group and both the FA ( $\mathrm{p}=$ $0.0001)$ and the VAS ( $p=0.0001)$ groups but no difference was found in TL,CO between the FA and the VAS groups $(\mathrm{p}=0.66)$ (fig. 1).

The median ${ }^{99 m}$ Tc-DTPA clearance was rapid in the FA group (21.25 $\mathrm{min}$ ) but normal in the VAS (46.5 min) and C (84.5 min) groups. In this regard, while all patients in the $\mathrm{C}$ group and 12 out of 14 in the VAS group had normal clearance, only three out of 14 patients in the FA group had normal levels. There was a significant difference in DTPA clearance between the FA and VAS groups $(\mathrm{p}=0.014)$ and between the FA and $\mathrm{C}$ groups $(\mathrm{p}=0.0004)$, but no difference was detected between the VAS and $\mathrm{C}$ groups (fig. 2).

Follow-up data, including lung function tests and HRCT scans, from the VAS group were available in 13 patients

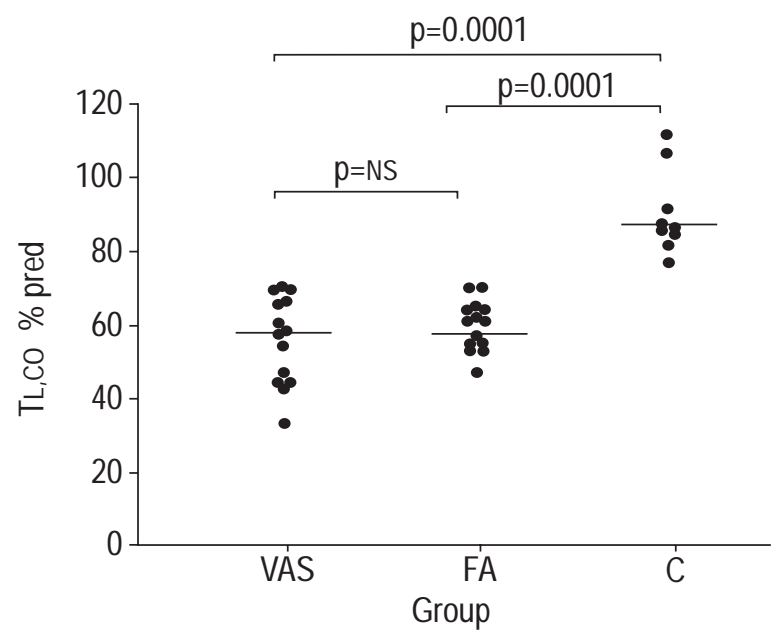

Fig. 1. - Total diffusion capacity of the lung for carbon monoxide $(T \mathrm{~L}, \mathrm{CO})$ expressed as percentage of predicted for the vascular (VAS), fibrosing alveolitis (FA) and control (C) groups. Median values are indicated for each group. Intergroup comparisons are shown with accompanying statistical significances.

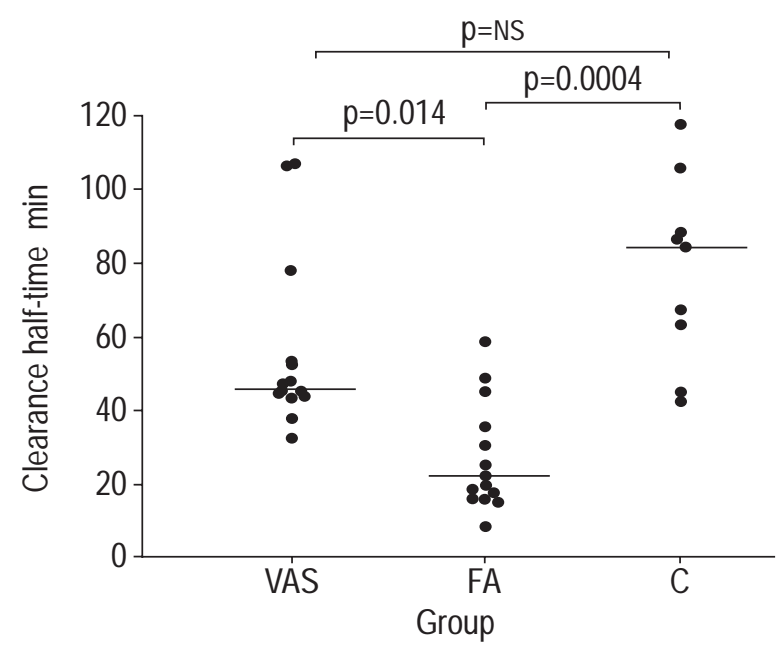

Fig. 2. - Technetium-99m-diethylenetriamine pentaacetate clearance half-times for the vascular (VAS), fibrosing alveolitis (FA) and control (C) groups. Median values are indicated for each group. Intergroup comparisons are shown with accompanying statistical significances.

and the mean time from initial assessment to the most recent HRCT and lung function measurement was 42 months (range 2-134 months). None of the follow-up VAS patients developed FA up to the time of the last follow-up, as assessed by normal HRCT and lung function volume measurements. All patients in the VAS group had a normal FVC in the subsequent months. Four patients died 1.5, 4, 36 and 43 months, respectively, after their first assessment, three of whom had documented evidence of pulmonary hypertension on echocardiography or cardiac catheterization (pulmonary artery pressure range $\sim 50-80 \mathrm{mmHg}$ ) during the period of follow-up. None of the patients in the VAS group were on any treatment with corticosteroids and/or immunosuppressive agents (table 2).

Antinuclear antibody data were available in all patients in the C group, 13 of the 14 VAS group patients and 12 of the 14 FA group patients. Sclerosis ( $\mathrm{Scl}$ )-70 antibodies were detectable in five patients in the FA group $(41.6 \%)$, one

Table 2. - Follow-up findings in the vascular group

\begin{tabular}{lccrcc}
\hline $\begin{array}{l}\text { Patient } \\
\text { No. }\end{array}$ & $\begin{array}{c}\text { Duration } \\
\text { months }\end{array}$ & HRCT & $\begin{array}{c}\text { FVC } \\
\% \text { pred }\end{array}$ & $\begin{array}{c}\text { TL,CO } \\
\% \text { pred }\end{array}$ & Notes \\
\hline 1 & 134 & $\mathrm{~N}$ & 93 & 67 & $\begin{array}{c}\text { No treatment } \\
2\end{array}$ \\
108 & & 131 & 70 & No treatment \\
3 & 14 & $\mathrm{~N}$ & 109 & 51 & Died \\
4 & 73 & $\mathrm{~N}$ & 160 & 41 & No treatment \\
5 & 2 & & 115 & 33 & Died \\
6 & 9 & $\mathrm{~N}$ & 87 & 51 & Died \\
7 & & & & & Died \\
8 & 42 & & 100 & 58 & Died \\
9 & 47 & $\mathrm{~N}$ & 114 & 80 & No treatment \\
10 & 28 & $\mathrm{~N}$ & 111 & 52 & No treatment \\
11 & 36 & $\mathrm{~N}$ & 109 & 39 & No treatment \\
12 & 14 & & & & No treatment \\
13 & 27 & $\mathrm{~N}$ & 120 & 53 & No treatment \\
14 & 13 & & 114 & 91 & No treatment \\
\hline
\end{tabular}

Length of follow-up with lung function or computed tomography scan following initial assessment. HRCT: high-resolution computed tomography; FVC: forced vital capacity; TL, CO: transfer factor of the lung for carbon monoxide; N: normal. 
patient in the VAS group $(7.69 \%)$ and one patient in the C group $(11 \%)$. Anticentromere antibodies were found in 10 patients in the VAS group $(76.9 \%)$, but they were not detected in either the FA or the C group (table 1).

\section{Discussion}

These results show that the ${ }^{99 \mathrm{~m}} \mathrm{Tc}-\mathrm{DTPA}$ clearance time is normal in a group of patients with SSc with a significant loss of transfer factor and normal CT scans, compared with the group with FA and a similar severity of lung disease, consistent with these features being due to vascular disease. Isolated decreases in diffusion capacity have been described in SSc $[7,9,19,20]$ and it is possible that they are either due to primary pulmonary vascular changes or reflect early parenchymal fibrosis. The present study has shown that there was no evidence for the development of FA on further follow-up visits in the VAS group and that DTPA scanning may play a role in identifying this group of patients with pulmonary vascular disease. Furthermore, the control group of patients with SSc and biopsy-proven and radiographic FA was matched with respect to lung volumes and TL,CO but had abnormal DTPA scans.

The specific mechanism of increased clearance times in FA is still unclear but has been thought to be secondary to the stretching of epithelial junctions in the alveolar wall as a result of fibrotic traction or lymphocytic infiltration [12, 21]. The present findings support the hypothesis that the alveolar-capillary barrier is intact in cases of SSc with vascular disease and that the alveolar epithelial integrity is significantly impaired in matching patients with parenchymal fibrosis.

Ten of the evaluated VAS subjects were positive for anticentromere antibodies, with only one subject having Scl-70 positivity. In contrast, all of the patients with diffuse fibrosis were found to be negative for anticentromere antibodies but five were Scl-70 antibody positive. These findings confirm that the isolated $T \mathrm{~L}, \mathrm{CO}$ reduction group with no FA was associated with anticentromere antibodies and pulmonary vascular disease [9].

The measurement of pulmonary technetium-99m-diethylenetriamine pentaacetate (DTPA) clearance is noninvasive and simple and has been demonstrated to be reproducible [22]. In the clinical setting of assessing breathless systemic sclerosis patients with isolated diffusion deficits on lung function testing, technetium-99m-DTPA scans may be a useful additional noninvasive measure to high-resolution computed tomography in confirming the suspicion of vascular disease rather than early fibrosing alveolitis being present in systemic sclerosis. Given that early fibrosing alveolitis may be below the sensitivity of high-resolution computed tomography, a normal technetium-99-DTPA clearance time may obviate the requirement for an open lung biopsy as the definitive diagnostic measure of the presence of fibrosing alveolitis or pure vascular disease in such patients. In addition, this measurement may potentially indicate vascular disease before the development of measurable pulmonary hypertension by other measures such as echocardiography. A normal technetium-99mDTPA clearance time in the context of isolated diffusion deficits may, therefore, help the clinician to decide on the subsequent follow-up of these patients, with particular regard to more frequent and specific measures of vascular disease such as echocardiography.

\section{References}

1. D'Angelo WA, Fries JF, Masi AT, Shulman LE. Pathologic observations in systemic sclerosis (scleroderma): a study of fifty-eight autopsy cases and fifty-eight matched controls. Am J Med 1969; 46: 428-440.

2. Weaver AL, Divertie MB, Titus JL. Pulmonary scleroderma. Dis Chest 1968; 54: 490-498.

3. al-Sabbagh MR, Steen VD, Zee BC, et al. Pulmonary arterial histology and morphometry in systemic sclerosis: a casecontrol autopsy study. J Rheumatol 1989; 16: 1038-1042.

4. Young RH, Mark GJ. Pulmonary vascular changes in scleroderma. Am J Med 1978; 64: 998-1004.

5. Salerni R, Rodnan GP, Leon DF, Shaver JA. Pulmonary hypertension in the CREST syndrome variant of progressive systemic sclerosis (scleroderma). Ann Intern Med 1977; 86: 394-399.

6. Yousem SA. The pulmonary pathologic manifestations of the CREST syndrome. Hum Pathol 1990; 21: 467-474.

7. Owens GR, Fino GJ, Herbert DL, et al. Pulmonary function in progressive systemic sclerosis: comparison of CREST syndrome variant with diffuse scleroderma. Chest 1983; 84: 546-550.

8. Stupi AM, Steen VD, Owens GR, Barnes EL, Rodnan GP, Medsger TAJ. Pulmonary hypertension in the CREST syndrome variant of systemic sclerosis. Arth-ritis Rheum 1986; 29: 515-524.

9. Steen VD, Graham G, Conte C, Owens G, Medsger TAJ. Isolated diffusing capacity reduction in systemic sclerosis. Arthritis Rheum 1992; 35: 765-770.

10. Murata I, Takenaka K, Yoshinoya S, et al. Clinical evaluation of pulmonary hypertension in systemic sclerosis and related disorders: a Doppler echocardiographic study of 135 Japanese patients. Chest 1997; 111: 36-43.

11. Harrison NK, Glanville AR, Strickland B, et al. Pulmonary involvement in systemic sclerosis: the detection of early changes by thin section CT scan, bronchoalveolar lavage and ${ }^{99 \mathrm{~m}}$ Tc-DTPA clearance. Respir Med 1989; 83 : 403-414.

12. Chopra SK, Taplin GV, Tashkin DP, Elam D. Lung clearance of soluble radioaerosols of different molecular weights in systemic sclerosis. Thorax 1979; 34: 63-67.

13. Wells AU, Hansell DM, Harrison NK, Lawrence R, Black $\mathrm{CM}$, du Bois RM. Clearance of inhaled 99m-Tc-DTPA predicts the clinical course of fibrosing alveolitis. Eur Respir J 1993; 6: 797-802.

14. Fanti S, De FA, Aloisi D, et al. Early pulmonary involvement in systemic sclerosis assessed by technetium-99mDTPA clearance rate. J Nucl Med 1994; 35: 1933-1936.

15. Subcommittee for scleroderma criteria of the American Rheumatism Association Diagnostic and Therapeutic Criteria Committee. Preliminary criteria for the classification of systemic sclerosis (scleroderma). Arthritis Rheum 1980; 23: 581-590.

16. Jones GJ, Royston D, Minty BD. The physiology of leaky lungs. Br J Anaesth 1982; 54: 705-721.

17. Quanjer PH. Standardised lung function testing. Bull Eur Physiopathol Respir 1983; 19: Suppl. 5, 1-95.

18. McHugh NJ, Whyte J, Artlett C, et al. Anti-centromere antibodies (ACA) in systemic sclerosis patients and their relatives: a serological and HLA study. Clin Exp Immunol 1994; 96: 267-274.

19. Catterall M, Rowell NR. Respiratory function in progressive systemic sclerosis. Thorax 1963; 18: 10-15.

20. Hughes DTD, Lee FI. Lung function in patients with systemic sclerosis. Thorax 1963; 18: 16-20.

21. Labrune S, Chinet T, Collignon MA, Barritault L, Huchon GJ. Mechanisms of increased epithelial lung clearance of DTPA in diffuse fibrosing alveolitis. Eur Respir J 1994; 7: $651-656$

22. Thunberg S, Larsson K, Eklund A, Blaschke E. ${ }^{99 \mathrm{~m}} \mathrm{Tc}-$ DTPA clearance measured by a dual head gamma camera in healthy subjects and patients with sarcoidosis. Studies of reproducibility and relation to bronchoalveolar lavage findings. Eur J Nucl Med 1989; 15: 71-77. 